\title{
Prevalence and determinants associated with healthcare-associated infections in long-term care facilities (HALT) in the Netherlands, May to June 2010
}

R Eilers (renske.eilers@rivm.nl)1,2, M J Veldman-Ariesen², A Haenen², B H van Benthem²

1. VU University, Amsterdam, the Netherlands

2. National Institute for Public Health and the Environment (RIVM), Bilthoven, the Netherlands

Citation style for this article:

Eilers R, Veldman-Ariesen MJ, Haenen A, van Benthem BH. Prevalence and determinants associated with healthcare-associated infections in long-term care facilities (HALT) in the Netherlands, May to June 2010. Euro Surveill, 2012;17(34):pii=20252. Available online: http://www.eurosurveillance.org/ViewArticle. aspx?Articleld $=20252$

Article submitted on 28 November 2011 / published on 23 August 2012

HAls (healthcare-associated infections) are likely to become an increasing public health problem. Therefore, a point-prevalence study called HALT (Healthcareassociated infections in long-term-care facilities) was set up by the European Centre for Disease Prevention and Control to determine the prevalence, antibiotic use and determinants associated with HAls. In the Netherlands, 10 nursing homes (in total 1,429 elderly residents) participated in the study between May and June 2010. Risk and protective factors were determined by calculating relative risks (RRs) and performing multilevel Poisson regression. An overall infection prevalence of $2.8 \%$ was found and $3.5 \%$ of the residents used antibiotics. Residents' characteristics such as the presence of pressure wounds (RR: 2.58 ; $95 \% \mathrm{Cl}$ : 1.04-6.39) and other wounds (RR: $5.70 ; 95 \%$ Cl: $2.99-$ 10.86) were risk factors for an HAI, whereas being male (RR: $0.43 ; 95 \% \mathrm{Cl}: 0.21-0.91$ ) was protective. Nursing home characteristics, such as the percentage of shared rooms ( $\geq 32 \%$ ) (RR: $0.49 ; 95 \% \mathrm{Cl}: 0.39-0.62$ ) and percentage of incontinent residents ( $\geq 63 \%)$ (RR: $0.72 ; 95 \% \mathrm{Cl}: 0.61-0.85)$ were protective determinants in a multivariate analysis. Special attention is therefore needed for female residents and residents with pressure and other wounds for the prevention of HAls in Dutch nursing homes.

\section{Introduction}

The European Centre for Disease Prevention and Control (ECDC) defines healthcare-associated infections (HAIs) as infections occurring after exposure to healthcare, often, but not always, as a consequence of this exposure [1]. HAls are a major challenge: in Europe, they are a frequent source of morbidity and mortality and the leading reason for residents of long-term-care facilities (LTCFs) to be hospitalised [2-4]. In Norway, the mortality rate and hospital admission rate due to HAIs during October 2004 and May 2005 were assessed at respectively 0.16 per 1,000 resident-care days and 0.35 per 1,000 resident-care days [5]. HAls may also have an impact on the quality of life of the residents in LTCFs $[4,6]$, but this hypothesis needs more research.
Elderly people are especially prone to HAls because their immune response may be diminished due to malnutrition, polypharmacy and the presence of multiple chronic diseases $[4,7]$. The most common HAls reported are respiratory, urinary, gastrointestinal, skin and tissue infections [2].

It is estimated that there are about 4 million HAls per year in hospitals and LTCFs in the European Union, leading to 37,000 deaths per year [1]. Meanwhile, the average age of the European population is rising: by 2060 , persons aged 60 years and above will account for $30 \%$ of the European population, compared with $17 \%$ in 2008 [8]. Moreover, persons aged 80 years and above will account for $12 \%$ of the European population in 2060 [8]. Of elderly people, this group have the most physical limitations and are therefore most likely to be moving into a nursing home [9]. As the aging of the European population will lead to more elderly people residing in nursing homes, it could be expected that the burden of HAls will rise [1]. Due to the interaction between populations inside and outside nursing homes, HAls in such homes are linked with infections in the general population and will become an increasing public health problem [10]. Furthermore, because of the HAls, antibiotics are used to a considerable extent in LTCFs [11,12]: such use leads to the occurrence of antibiotic-resistant pathogens in LTCFs $[12,13]$. Due to the frequent transfer of residents to hospitals, resistant pathogens can also be transferred from hospitals to nursing homes and vice versa [7].

In the Netherlands, LTCFs are homes for people who need intensive care, nursing, treatment, constant assistance due to chronic physical and mental problems and who are dependent in their activities of daily life. In Italy (winter months, published in 2007), Norway (June-October 2002 and June-October 2003), Ireland (May, 2010) and Germany (May-September 2010), the prevalence of HAls in such facilities has been shown to be $10.8 \%, 6.6-7.6 \%, 11.3 \%$ and $1.6 \%$, respectively [14-17]. Eikelenboom-Boskamp et al. found a mean HAI 
prevalence of $7.3 \%$ in nursing homes in the region of Nijmegen in the Netherlands from 2007 to 2009 (season unknown) [18].

In the Netherlands, a surveillance network has been set up to monitor the incidence of HAls in Dutch nursing homes, called SNIV (Surveillance Netwerk Infectieziekten Verpleeghuizen [Surveillance network infectious diseases nursing homes]) [19,20]. Participation in this network is voluntary.

Determinants associated with HAls have been identified in Italy, France/Switzerland, Germany and [14,21,22]. In order to gain more insight in HAls, a European point prevalence study was planned for 2009 to 2011 by ECDC, called HALT (Health-care associated infections in long-term care facilities). The aim of this project was 'to develop and implement a protocol for surveillance of $\mathrm{HAl}$, antimicrobial use and resistance in European LTCFs in order to establish baseline rates and identify priorities for improvement' [23]. This article presents the results of the HALT study in the Netherlands.

\section{Methods}

\section{Study design}

A total of 10 nursing homes of the 325 nursing homes in the Netherlands participated in the HALT study. At the time of the study, there were 25 nursing homes participating in the SNIV surveillance network: all 25 were invited to participate in the study, of which 10 agreed.

Data were collected at one point in time in each home between May and June 2010, following the HALT protocol [23]. One researcher visited all 10 homes, accompanied by one other researcher. All patients staying longer than 24 hours in the nursing home at the time the data were collected were included. Two questionnaires were used: one on the institution and one on the residents. The former, dealing with the characteristics of the home, was filled in by the nursing staff. The latter, completed by the researchers and nursing staff together, focused on characteristics of residents who had signs of an infection and/or used antibiotics.

In deviation from the HALT protocol, we defined having an infection as suspicion of infection. Suspicion of infection was defined as having at least one symptom or sign on the HALT score list [23]. We followed the HALT protocol in that three other criteria also had to be met: (i) all symptoms and signs had to be new or acutely worse; (ii) non-infectious causes of signs and symptoms were excluded; and (iii) identification of a sign or symptom was not based on a single piece of evidence. The signs and symptoms of infection in this study were recorded by the nursing staff who were present on each floor of the home. After collecting all the data, the presence of infection was also verified with the nursing home's general practitioner.

The following infections were recorded: gastrointestinal, urinary tract infections, systemic infections, respiratory tract infections, pneumonia/bronchial infections, unexplainable fever episodes, otorhinolaryngological infections and other infections.

\section{Data analysis}

For the purposes of data analysis, a resident was considered as having an infection or not (i.e. the type or number of infections was not taken into account). For urinary tract infections, a separate analysis was also performed. We included only the determinants that were described in the HALT protocol to identity any risk factors.

Using data from the resident and institutional questionnaires, the prevalence of infection and the use of antibiotics were determined. They were also used to identify resident characteristics as possible determinants. Data from the institutional questionnaire were used to identify nursing home characteristics as possible determinants.

The proportion of the nursing home characteristics (possible risk factors) was calculated using the total number of residents per nursing home. Then, the nursing home characteristics were dichotomised according to the mean values.

The proportions of residents who were incontinent, immobile or disorientated - which were considered as indicators of the burden of care - were included in the analysis to take into account any differences between the nursing homes. In the homes that participated in the study, the burden of care of their residents was found to be quite similar for incontinence and immobility; therefore, we chose to include only disorientation in the multivariate analysis as an indicator of the burden of care.

Poisson regression with a multilevel analysis was used to perform a multivariate analysis. The multilevel analysis consisted of including a nursing home identifier variable in the Poisson regression to take into account any differences that may have been present in the different nursing homes besides the variables we included to consider these differences. A Poisson distribution was used because the number of infections could be considered count data and no overdispersion was present.

Resident characteristics could not be analysed by regression analysis because no data were available on residents who did not show any signs of infection. Therefore, relative risks (RRs) were calculated from cross tabulation tables.

Characteristics that had $p$ values of $\leq 0.05$ in the univariate analysis were included in the multivariate analysis. A variable was considered a confounder when the regression coefficient changed more than $10 \%$. $P$ values of $\leq 0.05$ were considered significant when 
TABLE 1

Characteristics of residents of 10 nursing homes, HALT study, the Netherlands, May-June $2010(n=1,429)$

\begin{tabular}{|l|c|}
\hline Characteristic & Number (\%) \\
\hline Male & $451(32)$ \\
\hline Aged $>85$ years & $572(40)$ \\
\hline Had a urinary catheter & $165(12)$ \\
\hline Had a vascular catheter & $0(0)$ \\
\hline Had pressure wounds & $75(5)$ \\
\hline Had other wounds & $100(7)$ \\
\hline Disorientated & $840(59)$ \\
\hline Incontinent & $871(61)$ \\
\hline Wheelchair bound or bedridden & $819(57)$ \\
\hline Had an operation in the past 30 days & $45(3)$ \\
\hline Had been admitted to hospital in the past 3 months & $3(0.2)$ \\
\hline
\end{tabular}

HALT: health-care associated infections in long-term care facilities.

investigating potential effect modifiers. For the analyses, SAS software version 9.2 and Excel 2007 were used.

\section{Results}

\section{Study population}

In total, 1,429 elderly people (living in 10 nursing homes across the Netherlands) were included in the study. Table 1 shows their characteristics. The nursing homes were quite similar regarding the proportions of incontinent (median: 67\%; range: 47-76) and immobile (median: 58\%; range: $44-67$ ) residents, but not for those with disorientation (median: 58\%; range: 47-93).

In total, 40 residents showed signs of an HAl, giving an overall prevalence of $2.8 \%$ (range between the homes: $0.10-5.6 \%)$. Urinary tract infection was the most prevalent diagnosed infection, with 10 cases, giving an overall prevalence of $0.7 \%$. On average, antibiotics were used by 50 residents (range between nursing homes: $0-7 \%$ ). Moreover, of the 40 residents who showed signs of an HAI, 24 did not use antibiotics.

Of the 40 residents who had an infection, 31 were women and 9 were men. Of the 50 residents who used antibiotics, 32 were women and 18 were men. Female residents used significantly more antibiotics than men $(p=0.003)$ but did not show significantly more signs of infections $(p=0.50)$.

\section{Individual determinants}

Table 2 shows the results of the univariate analysis at the individual level. Sex, with male being a protective factor (RR: $0.43 ; 95 \% \mathrm{Cl}: 0.21-0.91$ ), the presence of pressure wounds (RR: $2.58 ; 95 \% \mathrm{Cl}: 1.04-6.39$ ) and the presence of other wounds (RR: $5.70 ; 95 \% \mathrm{Cl}$
2.99-10.86) were statistically significantly associated with having an HAI.

\section{Nursing home determinants}

Table 3 shows the univariate and multivariate Poisson regression analysis at nursing home level. The univariate model showed that residents in the homes that had $32 \%$ or more shared rooms had a statistically significant lower risk of an $\mathrm{HAl}$ than residents in homes with less than $32 \%$ shared rooms (RR: 0.46 ; $95 \mathrm{Cl}$ : $0.34-$ 0.62 ). The same was the case for residents in homes that had $3 \%$ or more residents who had had an operation in the past 30 days (RR: $0.62 ; 95 \% \mathrm{Cl}: 0.44-0.88$ ). Furthermore, residents in homes with $63 \%$ or more incontinent residents had a statistically greater risk of HAls than residents in homes with less than $63 \%$ of their residents incontinent (RR 1.59; $95 \% \mathrm{Cl}: 1.01-2.49$ ).

The multivariate model for the nursing home characteristics showed that residents in nursing homes that had $32 \%$ or more shared rooms were less at risk of acquiring an HAI (RR: $0.49 ; 95 \% \mathrm{Cl}: 0.39-0.62$ ). Similarly, residents in nursing homes where $63 \%$ or more of the residents were incontinent were at less risk of acquiring an HAI (RR: $0.72 ; 95 \% \mathrm{Cl}: 0.61-0.85$ ) (Table 3).

\section{Discussion}

In this study, the percentage of antibiotic use turned out to be higher than the prevalence of HAls. This could indicate a contribution to the existing antimicrobial resistance in nursing homes [12]. Other explanations could be that the residents without signs or symptoms were finishing their antibiotic treatment in order to prevent antibiotic resistance or that the antibiotics were being used prophylactically.

\section{TABLE 2}

Univariate analysis of potential determinants for healthcare-associated infections at individual level, HALT study, the Netherlands, May-June 2010

\begin{tabular}{|c|c|}
\hline Potential determinant & Relative risk $(95 \% \mathrm{Cl})$ \\
\hline Sex (men vs women) ${ }^{\star}$ & $0.43(0.21-0.91)$ \\
\hline Aged $>85$ years & $1.62(0.87-2.99)$ \\
\hline Had a urinary catheter & $1.62(0.83-2.42)$ \\
\hline Had pressure wounds* & $2.58(1.04-6.39)$ \\
\hline Had other wounds & $5.70(2.99-10.86)$ \\
\hline Disorientated & $0.58(0.31-1.07)$ \\
\hline Incontinent & $0.96(0.51-1.79)$ \\
\hline Had an operation in the past 30 days & $2.49(0.80-7.79)$ \\
\hline Wheelchair bound or bedridden & $N A^{a}$ \\
\hline
\end{tabular}

HALT: health-care associated infections in long-term care facilities; NA: not applicable.

No residents with an infection were wheelchair bound or bedridden.

Statistically significant ( $p<0.05)$. 


\section{TABLE 3}

Univariate and multivariate multilevel Poisson regression analysis of potential determinants for healthcare-associated infections at nursing home level, HALT study, the Netherlands, May-June 2010

\begin{tabular}{|c|c|c|}
\hline \multirow{2}{*}{$\begin{array}{l}\text { Potential determinant } \\
\text { (mean cut-off value) }\end{array}$} & Univariate analysis & Multivariate analysis \\
\hline & Relative risk $(95 \% \mathrm{Cl})$ & Relative risk $(95 \% \mathrm{Cl})$ \\
\hline Male ( $\geq 32 \%)$ & $0.75(0.42-1.31)$ & - \\
\hline Aged $>85$ years $(\geq 39 \%)$ & $0.64(0.39-1.07)$ & - \\
\hline Had a urinary catheter $(\geq 11 \%)$ & $0.86(0.49-1.54)$ & - \\
\hline Had pressure wounds ( $\geq 5 \%$ ) & $0.93(0.54-1.60)$ & - \\
\hline Had other wounds ( $\geq 7 \%$ ) & $1.15(0.66-2.00)$ & - \\
\hline Disorientated $(\geq 60 \%)$ & $0.74(0.42-1.59)$ & $0.92(0.64-1.34)$ \\
\hline Incontinent ( $\geq 63 \%)$ & $1.59(1.01-2.49)^{*}$ & $0.72(0.61-0.85)^{*}$ \\
\hline Wheelchair bound or bedridden ( $\geq 57 \%$ ) & $1.50(0.93-2.44)$ & - \\
\hline Operation in past 30 days ( $\geq 3 \%)$ & $0.62(0.44-0.88)^{*}$ & $1.14(0.81-1.59)$ \\
\hline Admission to hospital in past 3 months $(\geq 0.2 \%)$ & $0.69(0.36-1.33)$ & - \\
\hline Shared rooms ( $\geq 32 \%)$ & $0.46(0.34-0.62)^{*}$ & $0.49(0.39-0.62)^{\star}$ \\
\hline No person present with training in HAI prevention & $1.59(0.96-2.61)$ & - \\
\hline No protocol for MRSA infection & $1.13(0.83-1.54)$ & - \\
\hline No vascular catheter protocol & $0.76(0.4-1.46)$ & - \\
\hline No parenteral nutrition protocol & $0.82(0.47-1.44)$ & - \\
\hline No use of hand alcohol & $0.88(0.38-2.02)$ & - \\
\hline No use of disinfectant wipes & $0.76(0.4-1.46)$ & - \\
\hline
\end{tabular}

HAI: health-care associated infection; HALT: health-care associated infections in long-term care facilities; MRSA: meticillin-resistant Staphylococcus aureus.

* Statistically significant ( $p<0.05)$.

Pressure and other wounds at the resident level were associated with HAls. Our hypothesis is that people with pressure or other wounds have a lower health status and are therefore more susceptible to an HAI. The percentage of incontinent residents was shown to be a risk factor in the univariate analysis of the nursing home characteristics, whereas in the multivariate model, it was found to be a protective factor. Incontinent residents may have higher risk of infection because urine and faeces irritate and damage the skin, which can lead to incontinence-associated dermatitis [24]. We did not expect to find the amount of incontinent residents $(\geq 63 \%)$ to be protective. We think that the small size of the study population may have played a role. In addition, the amount of data is insufficient to allow stratified analyses, in order to determine more precisely how this can become a protective factor.

We also did not expect to find the amount of shared rooms $(\geq 32 \%)$ to be protective. We hypothesise that residents who live in a single room possesses certain characteristics - other than those investigated in this study (e.g. presence of co-morbidities) - that make them more vulnerable to infection than residents who live in shared rooms. Such characteristics need further investigation. The small number of characteristics investigated in this study could therefore be seen as a limitation of this study. However, point prevalence studies using minimal resources can provide valuable information, freeing resources that can be used for other studies and developing interventions. Point prevalence studies are frequently used to determine HAI prevalence and use of antimicrobial agents in nursing homes $[14,15,18,21,25,26]$.

There are other limitations to this study. We did not have details of the characteristics of residents who did not show signs of infection: such information would facilitate a multivariate analysis on the data collected in the resident questionnaire. This would give a better exploration of the potential determinants at the individual level. Moreover, the dichotomisation of the nursing home characteristics in our analysis causes (subtle) differences between nursing homes to be filtered out. Therefore, any effects that these differences would have on the risk of getting an infection are diminished. This is also another argument for collecting information in the future on additional characteristics of residents who do not show signs of infection. Furthermore, in the HALT study, a score list was used to determine the signs and symptoms of infection. In our analysis, we considered every sign and symptom of infection as an indicator of infection. This might have caused an overestimation of the prevalence. On the other hand, however, it is likely that we did not miss any infections this way. Lastly, the various HAls seen in our study were analysed together: thus, the characteristics of an individual or nursing home cannot be associated with 
a specific type of infection. Analysis of determinants of infection at the individual and nursing home level restricted to residents who were diagnosed with an urinary tract infection did not give reliable results: there seemed to be a lack of power (data not shown).

The mean HAI prevalence and level of antibiotic use seen in the study of Eikelenboom-Boskamp et al. in Nijmegen region in the Netherlands [18] were much higher than those seen in our study. In both studies, urinary tract infection was the most prevalent HAI. The prevalence of HAls measured in Norway (2002-2004, Italy (published in 2007) and Ireland (2010) was also higher than that seen in our study, whereas in Germany (2010), the prevalence was lower [14-17].

In our opinion, there are four possible explanations for the differences between these studies. The first is confounding by indication: it is possible that the Dutch nursing homes that chose to participate in the HALT study had already paid a lot of attention to the prevention HAls and therefore the prevalence was lower. The second is seasonality: performing a study in the winter could lead to different results compared with performing a study in the spring. Our study and in those carried out in Ireland and Germany were carried out in the spring/summer: the study in Norway was carried out in both spring and winter and the study in Italy in the winter. Third, nursing homes may differ across Europe: nursing homes in the Netherlands, for example, are very different from those in Italy and the United Kingdom (e.g. in terms of the population living in a nursing home and the function of the home) [27]. Last, the methodology of the studies were different, making it difficult to draw conclusions about differences in the results. The studies performed in Ireland and Germany were both part of the HALT study and the same methodology was used. In these two studies, infection (yes/no) was also defined as the presence of any sign or symptom of infection to estimate the HAI prevalence.

The determinants associated with HAls in long-term care facilities or geriatric institutions in five European studies $[14,16,21,22,28]$ are shown in Table 4 .

Strikingly, the study in Ireland [16] found similar results for resident characteristics that were risk factors. Furthermore, having skin conditions (ulcers), found to be a risk factor in the Norwegian study [28], was also identified as a risk factor at the individual level in our study.

In the Netherlands, special attention should be given to female residents and residents with pressure wounds and other wounds in order to prevent HAls in the nursing homes. Our results and those of other studies indicate that the overall health of a nursing home resident must be monitored and that specific control interventions must be developed in order to prevent HAls in such residents. Initiatives to do this have already been
TABLE 4

Protective and risk factors associated with

healthcare-associated infections in other European studies

\begin{tabular}{|l|c|c|}
\hline Country & Protective factors & \multicolumn{1}{|c|}{ Risk factors } \\
\hline Italy [14] & None & $\begin{array}{c}\text { Degree of dependency } \text {, the } \\
\text { presence of co-morbidities } \\
\text { and invasive devices }\end{array}$ \\
\hline Ireland [16] & None & $\begin{array}{c}\text { Urinary catheter, } \\
\text { incontinence, pressure } \\
\text { sores, other wounds, surgery } \\
\text { in the past 30 days }\end{array}$ \\
\hline $\begin{array}{l}\text { France, } \\
\text { [21] }\end{array}$ & $\begin{array}{c}\text { Presence of a } \\
\text { psycho-behavioural } \\
\text { disorder }\end{array}$ & $\begin{array}{c}\text { Nutrition abnormalities, } \\
\text { diabetes, chronic bronchitis, } \\
\text { swallowing disorders, } \\
\text { intravenous catheter, urinary } \\
\text { catheter and other catheters }\end{array}$ \\
\hline $\begin{array}{l}\text { Germany } \\
\text { [22] }\end{array}$ & None & $\begin{array}{c}\text { Urinary catheters, gastric } \\
\text { tubes, age }>\text { 8o years }\end{array}$ \\
\hline Norway [28] & None & $\begin{array}{c}\text { Bedridden or a stay of } \\
\text { <28 hours in the facility, } \\
\text { presence of chronic } \\
\text { heart disease, urinary } \\
\text { incontinence, an indwelling } \\
\text { catheter, a skin ulcer }\end{array}$ \\
\hline
\end{tabular}

The degree of dependency was derived from the number of disabilities for activities for daily living (ADL): 3-4 and 5-6 were risk factors [29].

set up in the Netherlands, in a surveillance system called PREZIES (Preventie van ziekenhuisinfecties door surveillance [Prevention of hospital acquired infection through surveillance]) $[30,31]$ and SNIV.

For future studies, we consider it necessary to also take in consideration other factors (such as co-morbidities and nutrition status at resident level and use of infection prevention measures at nursing home level) in order to explore which other characteristics play a role in acquiring an HAl. Then, the appropriate indicators for infection control practices could be determined and prevention strategies developed.

\section{Acknowledgments}

We thank the 10 Dutch nursing homes who participated in this study and Madieke van den Brand who helped with the collection of the data. 


\section{References}

1. European Centre for Disease Prevention and Control (ECDC). Annual epidemiological report on communicable diseases in Europe 2008. Stockholm: ECDC; 2008. Available from: http:// ecdc.europa.eu/en/publications/publications/0812_sur_ annual_epidemiological_report_2008.pdf

2. Matheï C, Niclaes L, Suetens C, Jans B, Buntinx F. Infections in residents of nursing homes. Infect Dis Clin North Am. 2007;21(3):761-72, ix

3. European Commission. Public consultation on strategies for improving patient safety by prevention and control of healthcare-associated infections. Luxembourg: European Commission. [Accessed 22 Feb 2011]. Available from:

4. http://ec.europa.eu/health/ph_threats/com/ cons01_txt_en.pdf

5. Richards C. Infections in residents of long-term care facilities: an agenda for research. Report of an expert panel. J Am Geriatr Soc. 2002;50(3):570-6.

6. Koch AM, Eriksen HM, Elstrøm P, Aavitsland P, Harthug S. Severe consequences of healthcare-associated infections among residents of nursing homes: a cohort study. J Hosp Infect 2009;71(3):269-74.

7. Warshaw G, Mehdizadeh S, Applebaum RA. Infections in nursing homes: assessing quality of care. J Gerontol A Biol Sci Med Sci. 2001;56(2):M120-3

8. Strausbaugh LJ. Emerging health care-associated infections in the geriatric population. Emerg Infect Dis. 2001;7(2):268-71.

9. European Commission. Europe in figures - Eurostat yearbook 2010. Luxembourg: Publications Office of the European Union; 2010. Available from: http://epp.eurostat.ec.europa.eu/cache/ ITY_OFFPUB/KS-CD-10-220/EN/KS-CD-10-220-EN.PDF

10. Herten LMv, Oudshoorn K, Perenboom RJM, Mulder YM, Hoeymans N. Gezondheidstoestand van bewoners van instellingen. [Health status of residents of institutions]. Delft: Netherlands Organisation for Applied Scientific Research (TNO); 2002. Dutch.

11. [10] de Boer AS, Coutinho RA. Public health and healthcareassociated infections in the Netherlands. J Hosp Infect. 2007;65 Suppl 2:133-8.

12. Strausbaugh LJ, Joseph CL. The burden of infection in longterm care. Infect Control Hosp Epidemiol. 2000;21(10):674-9.

13. Esposito S, Leone S, Noviello S, Lanniello F, Fiore M. Antibiotic resistance in long-term care facilities. New Microbiol. 2007;30(3):326-31.

14. European Centre for Disease Prevention and Control (ECDC). Annual epidemiological report on communicable diseases in Europe 2010. Stockholm: ECDC; 2010. Available from: http://ecdc.europa.eu/en/publications/Publications/1011 SUR_Annual_Epidemiological_Report_on_Communicable_ Diseases_in_Europe.pdf

15. Moro ML, Mongardi M, Marchi M, Taroni F. Prevalence of longterm care acquired infections in nursing and residential homes in the Emilia-Romagna Region. Infection. 2007;35(4):250-5.

16. Eriksen HM, Iversen BG, Aavitsland P. Prevalence of nosocomial infections and use of antibiotics in long-term care facilities in Norway, 2002 and 2003. J Hosp Infect. 2004;57(4):316-20.

17. Cotter M, Donlon S, Roche F, Byrne H, Fitzpatrick F. Healthcareassociated infection in Irish long-term care facilities: results from the First National Prevalence Study. J Hosp Infect. 2012;80(3): 212-6.

18. Wischnewski N, Mielke M, Wendt C. [Healthcare-associated infections in long-term care facilities. German results of the European prevalence study HALT]. Bundesgesundheitsblatt Gesundheitsforschung Gesundheitsschutz. 2011;54(11):114752. German.

19. Eikelenboom-Boskamp A, Cox-Claessens JH, Boom-Poels PG, Drabbe MI, Koopmans RT, Voss A. Three-year prevalence of healthcare-associated infections in Dutch nursing homes. J Hosp Infect. 2011 May;78(1):59-62.

20. National Institute for Public Health and the Environment (RIVM). SNIV. Surveillance Netwerk Infectieziekten Verpleeghuizen. [Surveillance network infectious diseases nursing homes]. Bilthoven: RIVM. [Accessed 22 Feb 2011]. Dutch. Available from: http:// www.sniv.nl

21. Brunner NA, Veldman-Ariesen MJ, Haenen A, van der Sande $\mathrm{H}$, Benthem $\mathrm{BH}$. Healthcare-associated infection surveillance in nursing homes in the Netherlands [abstract]. Clin Microbiol Infect. 2010;16:S409. Available from:

22. http://www.blackwellpublishing.com/eccmid2o/abstract. asp?id $=84530$

23. Michel JP, Lesourd B, Conne P, Richard D, Rapin CH. Prevalence of infections and their risk factors in geriatric institutions: a one-day multicentre survey. Bull World Health Organ. 1991;69(1):35-41.

24. Heudorf U, Schulte D. [Surveillance of nosocomial infections in a long-term care facility. Incidence and risk factors]. Bundesgesundheitsblatt Gesundheitsforschung Gesundheitsschutz. 2009;52(7):732-43. German.

25. European Centre for Disease Prevention and Control (ECDC). Healthcare-associated infections and antimicrobial use in European long-term care facilities. Stockholm: ECDC. [Accessed 1 Feb 2012]. Available from: http://halt.wiv-isp.be/default.aspx

26. Nix D, Haugen V. Prevention and management of incontinenceassociated dermatitis. Drugs Aging. 2010;27(6):491-6.

27. Blix HS, Bergman J, Schiøtt J. How are antibacterials used in nursing homes? Results from a point-prevalence prescription study in 44 Norwegian nursing homes. Pharmacoepidemiol Drug Saf. 2010;19(10):1025-30.

28. Moro ML, Mongardi M, Marchi M. Healthcare-related infections outside the hospital: a new frontier for infection control. New Microbiol. 2007;30(3):350-4.

29. Ribbe MW, Ljunggren G, Steel K, Topinková E, Hawes C, Ikegami N, et al. Nursing homes in 10 nations: a comparison between countries and settings. Age Ageing. 1997;26 Suppl 2:3-12.

30. Eriksen HM, Koch AM, Elstrøm P, Nilsen RM, Harthug S, Aavitsland $P$. Healthcare-associated infection among residents of long-term care facilities: a cohort and nested case-control study. J Hosp Infect. 2007;65(4):334-40.

31. Katz S, Downs TD, Cash HR, Grotz, RC. Progress in development of the index in ADL. Gerontologist. 1970;10(1):20-30.

32. National Institute for Public Health and the Environment (RIVM). PREZIES landelijk surveillance netwerk ziekenhuisinfecties. [Prevention of hospital acquired infection through surveillance]. Bilthoven: RIVM. [Accessed 21 Aug 2012]. Dutch. Available from: http://www.prezies.nl

33. van der Kooi TI, Manniën J, Wille JC, van Benthem BH. Prevalence of nosocomial infections in The Netherlands, 20072008: results of the first four national studies. J Hosp Infect. 2010;75(3):168-72. 
